\title{
The modal account of luck revisited
}

\author{
J. Adam Carter ${ }^{1}$ - Martin Peterson ${ }^{2}$
}

Received: 9 November 2015 / Accepted: 10 February 2016 / Published online: 17 March 2016

(C) The Author(s) 2016. This article is published with open access at Springerlink.com

\begin{abstract}
According to the canonical formulation of the modal account of luck [e.g. Pritchard (2005)], an event is lucky just when that event occurs in the actual world but not in a wide class of the nearest possible worlds where the relevant conditions for that event are the same as in the actual world. This paper argues, with reference to a novel variety of counterexample, that it is a mistake to focus, when assessing a given event for luckiness, on events distributed over just the nearest possible worlds. More specifically, our objection to the canonical formulation of the modal account of luck reveals that whether an event is lucky depends crucially on events distributed over all possible worlds-viz., across the modal universe. It is shown that an amended modal account of luck which respects this point has the additional virtue of avoiding a notable kind of counterexample to modal accounts of luck proposed by Lackey (2008).
\end{abstract}

Keywords Luck · Modal account of luck · Epistemic luck · Theories of luck · Safety

\footnotetext{
J. Adam Carter

j.adam.carter@ed.ac.uk

Martin Peterson

martinpeterson@tamu.edu

1 University of Edinburgh, Edinburgh, UK

2 Texas A\&M University, College Station, USA
} 


\section{The modal account of luck}

The notion of luck has broad relevance in contemporary philosophy, in particular in moral philosophy ${ }^{1}$, legal philosophy ${ }^{2}$, and epistemology. ${ }^{3}$ Two leading accounts of luck are what, following Lackey (2008), we can call the lack of control account of luck ${ }^{4}$ and the modal account of luck. The modal account, which characterizes luck in terms counterfactual robustness, has over the past decade ${ }^{5}$ gained considerable traction, and this is especially the case in recent mainstream epistemology. 6

Duncan Pritchard (2005, p. 128) articulates the modal account of luck as follows ${ }^{7}$ :

If an event is lucky, then it is an event that occurs in the actual world but which does not occur in a wide class of the nearest possible worlds where the relevant conditions for that event are the same as in the actual world.

The modal account has quite a bit of surface plausibility. Suppose, for example, you win a (fair) lottery. In virtue of what is this event lucky? The modal account tells us it's lucky because although the event of your winning the lottery obtains in the actual world, it doesn't obtain in a wide class of near-by possible worlds where the relevant initial conditions for this event are the same as in the actual world-viz., worlds where you continue to buy a lottery ticket, the lottery remains free and fair and with long odds,

${ }^{1}$ For classic discussions of the place of luck in moral philosophy, see Williams (1981) and Nagel (1979). $C f$. Hales (2015) for a recent criticism of leading contemporary accounts or moral luck.

2 See Hart (2008), Nozick (1974) and Dworkin (1981). For an overview, see Nelkin (2013).

${ }^{3}$ See Pritchard and Whittington (2015) for a collection of recent work on this topic. For some recent criticisms of the claim that knowledge excludes luck, see Hetherington (2013) and Baumann (2014). Cf. Madison (2011).

${ }^{4}$ The key idea here is that an event is lucky for a given agent just when it is significantly enough beyond that agent's control. For some representative defenses of this kind of view, see Riggs (2009), Zimmerman (1987). See Lackey (2008) for critical discussion.

5 This is largely due to the sustained defense of a modal account of luck in Pritchard (2005). For a recent criticism of the modal account, as well as the lack of control account, see Hales (2014).

${ }^{6}$ Epistemologists sympathetic with a modal account of luck typically embrace a safety condition on knowledge. The key idea is, put simply, that a belief is lucky in a way that is incompatible with knowledge provided the belief could easily have been incorrect given the conditions of its formation; and, correspondingly, a belief is known only if (given the relevant conditions of the belief's formation), the belief couldn't easily have been incorrect. Framed in the language of the modal account of luck, a safety condition [e.g. as articulated in the canonical form by Pritchard (2005)] proceeds as follows: S's belief is safe if and only if in most nearby possible worlds in which $\mathrm{S}$ continues to form her belief about the target proposition in the same way as in the actual world, the belief continues to be true. A safety condition on knowledge has been defended by various authors including Luper-Foy (1984), Sainsbury (1997), Pritchard (2005), Pritchard (2002), Pritchard (2008), Sosa (1999), Williamson (2000). See Rabinowitz (2011) for an overview.

7 A few pages later Pritchard (2005, p. 132) adds a second condition to his account, which is fulfilled in all examples discussed in this paper: "If an event is lucky, then it is an event that is significant to the agent concerned (or would be significant, were the agent to be availed of the relevant facts)." Pritchard (2015) has, more recently, dropped the significance condition from his proposal. The matter of significance is orthogonal to the kind of objection we raise to the proposal, so it won't concern us here. For some recent discussion on the relevance of a significance condition to an account of luck, see Ballantyne (2012) and Whittington (2015). For more general discussion of the relevance of psychology to a theory of luck, see Pritchard and Smith (2004). 
etcetera. ${ }^{8}$ As Pritchard $(2007,278)$ puts it: "Indeed, in most near-by possible worlds that meet this description, I am right now tearing up my lottery ticket in disgust." 9

Recent work in epistemology suggests that the modal account is in better shape than the lack-of-control account, but this point won't concern us here. ${ }^{10}$ Rather, we think the modal account - at least as it is canonically formulated - is open to an intractable sort of counterexample, one which has to this point been overlooked in the literature.

\section{A counterexample}

Imagine that some event E occurs: (i) in the actual world, and (ii) in a small class of the nearest possible worlds where the relevant conditions for $\mathrm{E}$ are the same as in the actual world. Also consider some other event $E^{*}$, which occurs (iii) in the actual world, and (iv) in the very same small class of previously mentioned nearest possible worlds, and (v) in every possible world located just a tiny bit further away. According to the canonical formulation of the modal account of luck, both $\mathrm{E}$ and $\mathrm{E}^{*}$ will be classed as equally lucky events. This is, however, a problematic conclusion.

In order to see why, note that $\mathrm{E}^{*}$ is surely less lucky than $\mathrm{E}$ because $\mathrm{E}^{*}$ occurs in many more worlds than E does. So suppose we construct the example such that the number of nearest worlds in which E occurs is just at the limit at which E would no longer count as a lucky event. That is, if E had occurred in, say, one or a few more of the nearest worlds, then E would not have been lucky. However, because E was in fact lucky, proponents of the modal account must concede that $\mathrm{E}^{*}$ is (by the same rationale) lucky too. But this is absurd. By construction, $\mathrm{E}^{*}$ occurs in the same worlds as $\mathrm{E}$ and in every possible world located just a tiny bit further way, and those somewhat more remote worlds should surely count for something.

In order to bring this point into sharp relief, imagine that you are in Edinburgh but wish to meet up with your sister in London tonight. You decide to take the East Coast Express from Edinburgh to London. To your surprise, the train actually arrives on time at 7.59 p.m. This event, call it E, is a lucky event because the East Coast Express usually arrives in London at least ten minutes after schedule. However, E is fairly close to being a non-lucky event. If the on-time performance had just been a little bit better,

\footnotetext{
8 Pritchard (2007, p. 278).
}

9 A reviewer has pointed out that it is unclear how Pritchard's expression "most nearby possible worlds" should be interpreted. The problem is that the set of nearby possible worlds is an infinite set, meaning that the term "most" has no mathematically well-defined meaning. We believe Pritchard could handle this technical objection by putting the mathematical notion of "density" to work. Consider, for instance, the claim that "there are more positive integers than perfect squares". It is true that the set of positive integers is no larger than the set of perfect squares: both sets are countably infinite. However, if we examine the positive integers one by one, starting with 1 , we will notice that the perfect squares become increasingly scarce. The mathematical notion of "density" can be used for describing this phenomenon. So when Pritchard writes that "in most near-by possible worlds.... I am right now tearing up my lottery ticket in disgust" we could read this to mean that of all the worlds that are similar to the actual world (to some specific degree) the density of the worlds in which Pritchard is tearing up his lottery ticket in disgust is higher than the density of the worlds in which he is the holder of a winning ticket.

10 A common style of objection to such proposals insists that they are too inclusive. For example, the sun's rising is entirely out of our control, yet, intuitively, it's not lucky for us each time it rises. See Lackey (2008) for this and other objections; $c f$. Broncano-Berrocal (2015) for recent critical discussion. 
E would have occurred in "too many" nearby possible world and would thus not have counted as lucky.

Now consider event $\mathrm{E}^{*}$. This is the event in which you arrive in London no later than 7.59 p.m. There is a very reliable express coach running from Peterborough to London that is scheduled to reach its destination before 7.59 p.m. In a large number of the possible worlds in which you sit on the East Coast Express you notice that the train is running late as it stops in Peterborough. In those worlds you therefore transfer to the express coach and arrive on time in London no later than 7.59.

Is event $\mathrm{E}^{*}$ a lucky event? Our intuition is that it is not. $\mathrm{E}^{*}$ occurs in the same worlds as $\mathrm{E}$ and in every possible world located just a tiny bit further way. Those somewhat more distant worlds make the scales tip over. $\mathrm{E}^{*}$ is not a lucky event.

We can also illustrate our point in a lottery example. Let $\mathrm{E}$ be the event that you win $£ 1000$ in your yacht club's annual lottery. Suppose that there are 100 winning tickets and that you buy one of them. If the total number of tickets in the lottery is of the right size, then $\mathrm{E}$ is a lucky event. Let us stipulate that if there had been just one or two more winning tickets in the lottery, then the proportion of winning tickets would have been so large that E would no longer have been a lucky event. By construction, $\mathrm{E}$ is right at the border between a lucky and non-lucky event.

Now imagine that $\mathrm{E}^{*}$ is the event that you win $£ 1000$ in your golf club's annual lottery. There are 100 winning tickets and if the total number of winning tickets is the same as above, meaning that if there had been just one or two more winning tickets then $\mathrm{E}^{*}$ would no longer have been a lucky event. However, unlike in the previous lottery, you will also win the $£ 1000$ prize in all of the somewhat more remote worlds in which some member of the club wins next year's British Open. ${ }^{11}$ Because the members of the golf club are amateurs, this is a more remote possibility than the event in which you happen to buy one of the 100 winning tickets. However, because the event in which you win $£ 1000$ was already on the verge of being non-lucky, this additional possibility of winning $£ 1000$ makes the scales tip over. Winning the $£ 1000$ is no longer a lucky event. Unfortunately, and for the reasons explained above, the canonical formulation of the modal account lacks the resources to account for this intuition.

The counterexamples outlined here are equally applicable if one accepts, as Pritchard (2015) Sosa (2015) and Carter (2016) have, that luck comes in degrees. In that case we construct the examples such that E occurs in the actual world and is lucky to degree $x$ ("very lucky", "somewhat lucky", etc.) although E is just at the limit at which an event is no longer lucky to degree $x$. While $\mathrm{E}$ and $\mathrm{E}^{*}$ both occur in the very same small class of previously mentioned nearest possible worlds, the difference between $\mathrm{E}$ and $\mathrm{E}^{*}$ is that the latter event also occurs in every possible world located just a tiny bit further away. Our intuition is that those somewhat more remote worlds count. Therefore, $\mathrm{E}^{*}$ is lucky to a lower degree than E. But the standard formulation of the modal account lacks the resources to acknowledge this. On the standard modal account, all that matters is what happens in the nearest worlds.

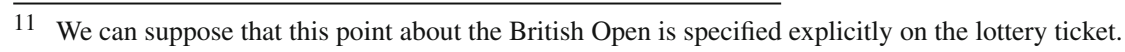


If one believes that luck is a vague concept, all one has to do to get the counter example to work is to make sure that $\mathrm{E}$ is a clear example of a lucky event and $\mathrm{E}^{*}$ is a clear example of a non-lucky event. The fact that there might be a borderline area in between the two events makes no difference, as long as the difference between $\mathrm{E}$ and $\mathrm{E}^{*}$ is large enough.

\section{Lackey's counterexample}

Jennifer Lackey (2008) has proposed a different counterexample to the modal account of luck. It goes as follows:

BURIED TREASURE: Sophie, knowing that she had very little time left to live, wanted to bury a chest filled with all of her earthly treasures on the island she inhabited. As she walked around trying to determine the best site for proper burial, her central criteria were, first, that a suitable location must be on the northwest corner of the island-where she had spent many of her fondest moments in life - and, second, that it had to be a spot where rose bushes could flourishsince these were her favorite flowers. As it happens, there was only one particular patch of land on the northwest corner of the island where the soil was rich enough for roses to thrive. Sophie, being excellent at detecting such soil, immediately located this patch of land and buried her treasure, along with seeds for future roses to bloom, in the one and only spot that fulfilled her two criteria. One month later, Vincent, a distant neighbor of Sophie's, was driving in the northwest corner of the island - which was also his most beloved place to visit—and was looking for a place to plant a rose bush in memory of his mother who had died ten years earlier-since these were her favorite flowers. Being excellent at detecting the proper soil for rose bushes to thrive, he immediately located the same patch of land that Sophie had found one month earlier. As he began digging a hole for the bush, he was astonished to discover a buried treasure in the ground (Lackey 2008, p. 261).

Lackey's point is that Vincent's discovery of the buried treasure is an example of a lucky event, even though it does not satisfy the conditions for a lucky event as specified by the modal account. ${ }^{12}$ The problem is that the event that Lackey considers to be lucky

\footnotetext{
12 Pritchard (2015; 2005, p. 144, fn. 15) himself has expressed doubt that Lackey's BURIED TREASURE case is a case of bona fide luck. For one thing, Pritchard has suggested the case might be importantly ambiguous on the matter of both (i) the size of the patch of land Sophie locates; and (ii) how deeply the treasure was buried. He suggests that these ambiguities could be removed by stipulating "that the areas on the island where one might bury treasure all come in distinct patches not much bigger than the treasure itself, and that the soil on these patches becomes too hard to turn very quickly, so that the treasure cannot be buried very deep $[\ldots]$ such that if anyone chose the patch of land in which the treasure was buried to dig (for whatever reason, including to plant a shrub), they would find the treasure. Now we further stipulate that there is only one patch of land on the island which is suitable for planting rose bushes, and that it is obvious that this is so to anyone who knows about these things." Pritchard's line is that once these details are filled in, we are less inclined to regard the event as lucky. Rather, he suggest, we might say the event was fortunate. Cf., Pritchard's (2005, p. 144, fn. 15) for a similar kind of response to a to a case put forward by Nicholas Rescher (1995, p. 35).
} 
Fig. 1 a By construction, this event (E) is lucky but very close to not being lucky. b According to the modal account this event $\left(\mathrm{E}^{*}\right)$ is also lucky because it occurs in equally many of the nearest possible worlds.

However, our intuition is that it is not lucky: it occurs in so many more remote worlds that the scales tip over
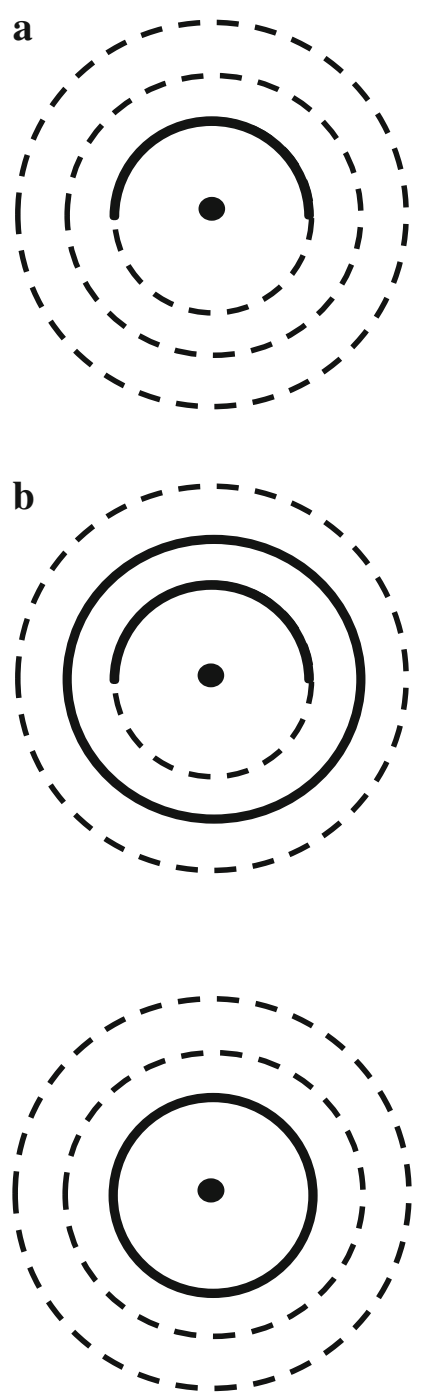

Fig. 2 In Lackey's example the event is lucky despite the fact that it occurs in all the nearest possible worlds

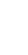

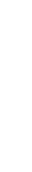




\section{Saving the modal account: modal weighted likelihood}

What can we learn from these counterexamples? Unlike Lackey, we do not believe that every modal account of luck is doomed to fail. On the contrary, it seems that the following revised version of the modal account can overcome both counterexamples: If an event is lucky, then it is an event that occurs in the actual world but whose modal weighted likelihood is above some appropriate threshold.

The term "modal weighted likelihood" refers to a measure that considers which worlds E occurs in and the distance of those worlds from the actual world, such that (i) the weight assigned to the occurrence of $\mathrm{E}$ in a world decreases as the distance from the actual world increases, and (ii) an event is less lucky the more worlds it occurs in, everything else being equal.

When making the notion of modal expected likelihood sharp, we have to keep in mind that we are dealing with an infinite number of possible worlds. This creates some technical difficulties. If, for instance, both E and not-E occur in infinitely many worlds this should not lead us to believe that E and not-E are equally lucky. This is because the density of E-worlds might be much lower than the density of not-Eworlds. The mathematical example mentioned in footnote 9 suffices for explaining this point: We know that the countably infinite set of positive integers is no larger than the countably infinite set of perfect squares. Despite this, the perfect squares become increasingly scarcer as we move upwards from 1 towards infinity. There is, therefore, a sense in which one is luckier if one by random happens to pick a perfect square than a non-perfect square. Mathematicians use the notion of density for articulating the observation that the perfect squares are scarcer than the positive integers. For our present purposes an intuitive understanding of density will be sufficient. ${ }^{13}$

Let $d(\mathrm{E}, \mathrm{x})$ denote the density of $\mathrm{E}$ at distance $\mathrm{x}$ from the actual world. For each distance $\mathrm{x}$ from the actual world, $d(\mathrm{E}, \mathrm{x})$ assigns a value $[0,1]$ that represents the density of E-worlds at distance $\mathrm{x}$ from the actual world, such that $d(\mathrm{E}, \mathrm{x})=0$ if and only if $\mathrm{E}$ occurs in no world at distance $\mathrm{x}$, and $d(\mathrm{E}, \mathrm{x})=1$ if and only if $\mathrm{E}$ occurs in all worlds at distance $\mathrm{x}$.

Let $w(\mathrm{x})$ denote the weight assigned to events that occur at distance $\mathrm{x}$ from the actual world. It is plausible to assume that $w(\mathrm{x})$ approaches 0 as $\mathrm{x}$ approaches $\infty$ and that $w(\mathrm{x})$ approaches 1 as $\mathrm{x}$ approaches 0 . The expected modal likelihood $\mathrm{ml}$ of $\mathrm{E}$ can then be defined as follows:

$$
m l(\mathrm{E})=\int_{x=0}^{\infty} w(x) \cdot(1-d(E, x))
$$

It can be easily verified that the expected modal likelihood measure has a number of attractive properties:

Property 1 If E occurs in the actual world but in no other possible world, then $E$ is maximally lucky: $m l(\mathrm{E})=\int_{x=0}^{\infty} w(x)$.

13 For a formal definition and discussion of the notion of density, see Chapter 16 in Nathanson (2000). 
Property 2 If E occurs in the actual world and in all other possible worlds, then $E$ is minimally lucky (that is, not lucky at all): $m l(\mathrm{E})=0 .{ }^{14}$

Property 3 If $\mathrm{E}_{1}$ occurs in the actual world and with density d in the possible worlds at distance $\mathrm{x}_{1}$, and $\mathrm{E}_{2}$ occurs in the actual world and with the same density $d$ in the possible worlds at distance $\mathrm{x}_{2}$, and the worlds at distance $\mathrm{x}_{2}$ are further away than the worlds at distance $\mathrm{x}_{1}$, then $\mathrm{E}_{1}$ is more lucky than $\mathrm{E}_{2}: m l\left(\mathrm{E}_{1}\right)=k \cdot w\left(\mathrm{x}_{1}\right)>$ $m l\left(\mathrm{E}_{2}\right)=k \cdot w\left(\mathrm{x}_{2}\right)$.

Property 4 If $\mathrm{E}_{1}$ occurs in the actual world and in some possible worlds at distance $\mathrm{x}_{1}$, and $\mathrm{E}_{2}$ occurs in the actual world and in some possible worlds at distances $\mathrm{x}_{2}$ and $\mathrm{x}_{3}$, such that $\mathrm{x}_{3}>\mathrm{x}_{1}>\mathrm{x}_{3}$, then $\mathrm{E}_{1}$ and $\mathrm{E}_{2}$ will be equally lucky events for some $d\left(\mathrm{E}_{1}, \mathrm{x}_{1}\right), d\left(\mathrm{E}_{2}, \mathrm{x}_{2}\right)$, and $d\left(\mathrm{E}_{2}, \mathrm{x}_{3}\right)$ provided that $d$ is a continuous function.

The modal expected likelihood account is non-binary in that it allows for degrees of luck. ${ }^{15}$ By selecting a suitable threshold $\mathrm{T}$ this account can be turned into a binary notion of luck by stipulating that $\mathrm{E}$ is lucky if and only if $m l(\mathrm{E})>\mathrm{T}$.

The modal weighted likelihood account of luck gives the right answer in our lottery example. Because $\mathrm{E}^{*}$ occurs in many more worlds, the density of this event is high. Therefore, our account is able to explain why $\mathrm{E}$ is lucky and $\mathrm{E}^{*}$ is not. Furthermore, the new account also gives the right answer in Lackey's example. Although Sophie and Vincent were almost certain to dig in the same spot, Vincent's modal weighted likelihood of finding Sophie's treasure was low. ${ }^{16}$ By acknowledging that events in all

\footnotetext{
${ }^{14}$ A potential counterexample to this property has been proposed by Hales (2014), who argues that there are lucky necessities, i.e. lucky events that occur in all possible worlds. One of the examples he mentions is Pierre de Fermat's flawed proof of his famous theorem, which was correctly proved in 1995 by Hales (2014, p. 6) writes that "Fermat was lucky that his last theorem was true, despite his flawed proof, because it secured his mathematical immortality." We disagree with this characterization. The necessary truth "Fermat's last theorem is true" was not lucky. It was the contingent event "Fermat's last theorem was proved in 1995 by Andrew Wiles" that was lucky.

15 See Carter (2016) for some discussion for why this is an important desiderata on a plausible account of luck.

16 Consider, for example, that there are a vast number of worlds in which either Sophie or Vincent would not have been digging at all, or would not have visited the island, or would have been dead, and so on. Cf., Levy (2009) for a different intuition about the case, according to which Lackey's diagnosis conflates luck with fortune, a more general point which has also been raised independently by Coffman (2007, p. 392). As Levy sees it, fortune "refers to the non-chancy, and therefore not lucky, effects of luck, whether luck in events or circumstantial or constitutive luck. It is not itself lucky, but it is luck-involving, and therefore easily confused with luck" (Levy 2009, p. 496). Levy says, further, that "Fortune requires luck in the causal history of an event, but—as we have seen —an event having luck in its causal history is not necessarily a lucky event. Fortunate events are non-lucky events with luck in their proximate causes." Levy thinks Lackey's BURIED TREASURE case is one of (luck involving) fortune but does not itself pick out a case featuring bona fide luck. As he puts it, the luck "precedes the event upon which Lackey focuses." We submit that this distinction, and associated explanation, is also going to rule genuine cases of luck as merely fortunate, and luck-involving, but not lucky. This point can be made with reference to a simple bowling example. Suppose you leave a ' $7-10$ ' split. If one hits the 10 pin with a certain velocity and at just the right angle, the 10 pin will hit the 7 pin in most nearby worlds. However, even the most skilled professionals cannot come close to reliably hitting the 10 pin within the very small angle/velocity range which is necessary to convert the split. Thus, when they do hit the 10 pin at such an angle, it is a matter of luck, even if a general competence to bowl well is manifested when the ball is released. But, given that picking up the split involves the (high
} 
possible worlds count, advocates of the weighted likelihood account can explain why Vincent's discovery of the buried treasure was a lucky event.

\section{Conclusion}

There are many advantages to thinking about luck in terms of counterfactual robustness rather than control, and these advantages recommend a modal account of luck. We hope to have shown, however, that standard formulations of the modal account of luck face a hitherto unexplored problem, one which is highlighted by the counterexamples we raise in Sect. 2. The problem, in short, can be stated simply: it is a mistake for traditional modal accounts of luck to focus, when assessing a given event for luckiness, on events distributed over just the nearest possible worlds. However, rather than to abandon the modal account, as Lackey has recommended, we've opted for a more attractive way to defend the modal account, the modal weighted likelihood model, which avoids the objection we raise to the traditional construal of the account. Moreover, we've shown how the modal weighted likelihood model also has a further advantage: the account can straightforwardly handle another kind of counterexample which Lackey regards as devastating to the traditional formulation.

Open Access This article is distributed under the terms of the Creative Commons Attribution 4.0 International License (http://creativecommons.org/licenses/by/4.0/), which permits unrestricted use, distribution, and reproduction in any medium, provided you give appropriate credit to the original author(s) and the source, provide a link to the Creative Commons license, and indicate if changes were made.

\section{References}

Ballantyne, N. (2012). Luck and interests. Synthese, 185(3), 319-334.

Baumann, Peter. (2014). No luck with knowledge? On a dogma of epistemology. Philosophy and Phenomenological Research, 89, 523-551.

Broncano-Berrocal, F. (2015). Luck as risk and the lack of control account of luck. Metaphilosophy, 46(1), $1-25$.

Carter, J. A. (2016). Robust virtue epistemology as anti-luck epistemology: A new solution. Pacific Philosophical Quarterly, 97(1), 140-155.

Coffman, E. J. (2007). Thinking about Luck. Synthese, 158(3), 385-98.

Dworkin, R. (1981). What is equality? Part 2: Equality of resources. Philosophy \& Public Affairs, 10, 283-345.

Hales, S. D. (2014). Why every theory of luck is wrong. Noûs, 49, 1-19.

Hales, S. D. (2015). A problem for moral luck (pp. 1-19). New York: Springer. doi:10.1007/ s11098-014-0417-6.

Hart, H. L. A. (2008). Punishment and responsibility: Essays in the philosophy of law. Oxford: OUP Oxford. Hetherington, S. (2013). There can be lucky knowledge. In M. Steup, J. Turri, \& E. Sosa (Eds.), Contemporary debates in epistemology (2nd ed., p. S7). Oxford: Wiley-Blackwell.

Lackey, J. (2008). What luck is not. Australasian Journal of Philosophy, 86(2), 255-267.

Footnote 16 continued

probability) effect that the 7-pin also falls (once the 10 pin is hit in just the right way), Levy's account rules that that it's fortunate, but not lucky, that the 7 pin fell. This is counterintuitive, though, as the picking up of the entire split (the entire 7-10 split) is a paradigmatic case of a lucky event. See here also fn. 10. 
Levy, N. (2009). What, and where, luck is: A response to Jennifer Lackey. Australasian Journal of Philosophy, 87(3), 489-497.

Luper-Foy, S. (1984). The epistemic predicament: Knowledge, nozickian tracking, and scepticism. Australasian Journal of Philosophy, 62(1), 26-49.

Madison, B. (2011). Combating anti anti-luck epistemology. Australasian Journal of Philosophy, 89(1), 47-58.

Nagel, T. (1979). Mortal questions. Cambridge: Cambridge University Press.

Nathanson, M. B. (2000). Elementary methods in number theory., Graduate texts in mathematics Berlin: Springer.

Nelkin, D. K. (2013). Moral luck. In: E. N. Zalta (Ed.), The stanford encyclopedia of philosophy. http:// plato.stanford.edu/archives/win2013/entries/moral-luck/.

Nozick, R. (1974). Anarchy, state and utopia. New York: Basic Books.

Pritchard, D. (2002). Resurrecting the Moorean response to the sceptic. International Journal of Philosophical Studies, 10(3), 283-307.

Pritchard, D. (2005). Epistemic luck. Oxford: Oxford University Press.

Pritchard, D. (2007). Anti-luck epistemology. Synthese, 158(3), 277-297.

Pritchard, D. (2008). Radical scepticism, epistemic luck, and epistemic value. Aristotelian Society Supplementary Volume, 82, 19-41.

Pritchard, D. (2015). The modal account of luck. In D. Pritchard \& L. Whittington (Eds.), The philosophy of luck. London: Routledge.

Pritchard, Duncan, \& Smith, Matthew. (2004). The psychology and philosophy of luck. New Ideas in Psychology, 22(1), 1-28.

Pritchard, D., \& Whittington, L. (Eds.). (2015). The philosophy of luck. Hoboken: Wiley.

Rabinowitz, D. (2011). The safety condition for knowledge. Internet Encyclopedia of Philosophy.

Rescher, Nicholas. (1995). Luck: The brilliant randomness of everyday life. New York: Farrar, Strauss and Giroux.

Riggs, W. (2009). Luck, knowledge, and control. In D. Pritchard, A. Haddock, \& A. Millar (Eds.), Epistemic value (pp. 204-221). Oxford: Oxford University Press.

Sainsbury, R. M. (1997). Easy possibilities. Philosophy and Phenomenological Research, 57, 907-919.

Sosa, E. (1999). How to defeat opposition to Moore. Noûs JSTOR, 33, 141-153.

Sosa, E. (2015). Judgment and Agency. Oxford: Oxford University Press.

Whittington, L. (2015). Luck, knowledge and value. Synthese, 42, 1-19.

Williams, B. (1981). Moral luck: Philosophical papers 1973-1980. Cambridge: Cambridge University Press.

Williamson, Timothy. (2000). Knowledge and its limits. Oxford: Oxford University Press.

Zimmerman, Michael J. (1987). Luck and moral responsibility. Ethics, 97(2), 374-386. 